\title{
Sustainable Housing: A Preferred Approach to the Request of Housing Facility in Nigeria
}

\author{
Omotayo Adebayo Onanuga ${ }^{1}$, Collins Akugbe Oviasogie ${ }^{2}$ \\ ${ }^{1}$ Department of Architecture, Federal University of Technology, Akure, Nigeria \\ ${ }^{2}$ Department of Architecture, Ambrose Alli University, Ekpoma, Nigeria \\ Email: oaonanuga@futa.edu.ng, llincsu2@gmail.com
}

How to cite this paper: Onanuga, O.A. and Oviasogie, C.A. (2019) Sustainable Housing: A Preferred Approach to the Request of Housing Facility in Nigeria. Journal of Environmental Protection, 10, 337-351. https://doi.org/10.4236/jep.2019.102019

Received: December 4, 2018

Accepted: February 24, 2019

Published: February 27, 2019

Copyright ( 2019 by author(s) and Scientific Research Publishing Inc. This work is licensed under the Creative Commons Attribution International License (CC BY 4.0).

http://creativecommons.org/licenses/by/4.0/

\section{cc) (i) Open Access}

\begin{abstract}
Exhaustive studies have investigated housing situation in Nigeria in terms of demands, supplies, deficits, standard, finance, delivery and affordability. However, little or no studies have been done on how the housing that has and needs to be provided will give a long time satisfaction to the changing needs of users across their lifetime. The investigation of longtime satisfaction in building instigated by changing needs that result from ageing progression is necessary as studies have reported an inevitable biological and mental change in the users. This study investigated for such design type that would be compliant to the changing needs as the users grew in it, explored the knowledge of the design professionals and users on such design type and examined areas that improvements could be affected. 400 cases of houses designed and built by professionals and the ones with full participation of the end users in four geopolitical zones in Nigeria were examined using open-ended and closeended interview questions on the occupants. The houses selected were owneroccupied and the occupants had lived for at least 10 years in it. The result shows that neither do the professional nor the participated users consider ageing progression during design and construction stage, thereby, resulting in the increasing desire to modify the interior spaces as the occupants grow in it. Suggestions were made on how considerations could be given to ageing process during the design stage and the need for further investigation on the subject matter.
\end{abstract}

\section{Keywords}

Ageing Progression, Housing, Nigeria, Residential Building

\section{Introduction}

Housing is a rigid casing that encloses and protects pieces of living and move- 
able or immoveable elements. It is a crucial life component system designed to shelter and provide functions such as safety, warmth and place of rest [1]. House is one of the basic necessities that have a very close effect on human lives. The importance of housing overlaps with health and many other social, economy and environment aspects that sustain or ease the life of an individual, especially at old age [2].

A house and housing that can meet the physical, social, environmental and economic needs of people help to address housing dissatisfaction that results in a modification in the later year. These physical and other needs, being the critical considerations of sustainability studies, define the ability of a house to seem natural in function, remain diverse, produce satisfaction needed and balance in all nature of use now and in future to come. Therefore, achieving a sustainable environment involves a sustainable house and housing [3].

Several studies have defined sustainable housing as a design product that reduces overall environmental impacts during and after construction in such a way that a present need is met without compromising the ability to meet the future generation needs [4] [5]. Also, various approaches, measured in a different context and serving different purposes, have been deployed by previous researchers in investigating the sustainability of housing development. For instance, sustainability has been evaluated from the perspective of affordable housing [6], public housing program [7] and even from low carbon housing [8].

Also, [9] through analytic framework assessed sustainable housing using location, construction and design, energy efficient and housing regeneration as sustainable indicators, while decision matrixes such as safety, access to leisure, employment, transport services were used by [6]. Overall, the physical, social, economic and environment are four dimensions that have been used to assess sustainable housing development.

However, the view of this study looks into the ability of a housing design product to meet the present need of the occupant without compromising the future needs of the same occupant. Needs changes as people grow, forming the bases for housing demand and people's objectives of developing their houses. Human, the occupants of a design product, experiences biologically, socially and culturally change as they grow older and the needs in housing changes being influence by ageing factors that become more obvious as individual experience biological growth [10]. Factors such as decreasing mobility, declining physical strength, loss of vigour and increasing frailty are ageing factors that affect individuals in ways that impact their preferred choice of housing [11]. When these ageing factors become palpable, it often shows the need for some support or adaptation for the present housing products to be suitable [12] [13]. These ageing factors show that understanding the needs of the people, as well as their idea is an important indicator that can increase the life of housing, decrease cost and reduces social and environmental impacts.

With the present population size in Nigeria, scholars' reports have shown the need to build like one million houses annually, emphasising on suitable and af- 
fordable housing type. Meanwhile, the beauty of the demand lies in the ability of the housing product demanded to meet the changing need of the occupants across their lifetime, therefore, necessitate the need to examine how well the existing residences have fared so far. Studies have shown the inadequacies of the available housing such as the need for modification to augment for housing deficiencies, neglect of some spaces in the house due to lack of compatibility, and relocation in some worse situation among others [14] [15] [16]. This mandates the need to address the factors responsible for the declining users' satisfaction, with the view to better improve on the emerging houses demanded that will not just meet present needs but sustainable across users' lifetime.

Given this, the study uses the effect of users' socio-economic status, the indoor living condition and building materials used for construction to assess the sustainability of existing housing development. This is done to evaluate factors responsible for the declining satisfaction of design product and to investigate the parameter for a design product that will be compliant with the growing trend in the age of occupants. A quantitative technique through the use of structured interview was used for the study. The reliability of this method lies in the fact that verbal and non-verbal responses are recorded and the expression on the respondent's face can be judged when some specific questions are asked.

\section{Literature Review}

This section review the housing needs in Nigeria and the involvement of the different governing body in the past few decades using various related publications and textbooks. Also, the traditional design consideration was a review, and the emerging issues in housing provision and demands which revolves around human lifestyle, building materials and sustainability were related to past studies.

\subsection{Reviewing the Housing Need in Nigeria}

The involvement of the government in housing the vast populated Nigerians from the colonial period to the period of civilian administration has deployed different housing schemes through national development plans. These schemes have resulted in some good effort, though yet grossly inadequate, with many failures caused by factors such as site acquisition, expensive contractual procedures and inflations in labour cost, budget cut and insufficient capacity of construction industries, building technology and material choices [17] [18].

In just two decades of 1990-2010, the Nigeria housing deficit rose from 7 million to 14 million and still increasing [18]. The hope and expectation are that an effective and sustainable housing delivery system will be established in Nigeria, which will facilitate the mobilisation of long-term funds for shelter (housing units, infrastructure and social facilities) development especially that targeted at the urban poor. Consequently, it is imperative that studies be done on how the housing facilities aimed for will be sustainable.

Previous studies have shown that habitability depends not only on the physi- 
cal building characteristics, but also on the social, cultural, and behavioural aspects of the users [19] [20] [21] [22]. This means that the perception of quality in housing and its implication on satisfaction is crucial to the measure of an individual's quality of life [23]. Unfortunately, reports and studies like the [24] and [16], coupled with experiences such as the Gwari people's abandonment of an alternative resettlement housing scheme in Abuja revealed that the present housing units have poor user rating regarding perceived quality and satisfaction [16] [22] [25].

The poor perception, in most cases, is associated with the changing biological nature of humans. For instance, the implication of stairs on kneeling and hips, shortness of breath and the likes caused by loss of muscles at sixth decades of a person's life may make the house becomes unsuitable any longer. Other occurrences such as frailty that calls for reduced house size, failing eyesight that is affected by the change in levels in the building, hearing loss that makes it difficult to live in a sprawling house are just a few of all biological issues that have shaped current housing situation become inappropriate. Therefore, a housing system that is sustainable must be able to accommodate the biological change in the users; else modification will be inevitable. Where the cost of modification is not affordable, a situation of partial neglect or eventual abandonment might result.

\subsection{The Design Considerations for a Sustainable Housing}

The housing built for a lifetime living may be desirable at an early stage of life but become inappropriate at the threshold of old age. The concept of sustainable housing entails giving a supportive measure to the inevitable biologically changes experienced relative to ageing progression. This biological change reduces the level of independence as people grow, and increase the need for support in carrying out daily activities of living in their environment. When the characteristics of the residential housing are not supportive, the building is perceived as being no longer appropriate, and alternative means of promoting the development of active ageing is sort.

Apart from some special issues such as morbidity or disability, old age is generally accompanied by degenerative weaknesses in muscle, sight, hearing, and feeling, among others [26]. These weaknesses result in diminished mobility, the difficulty of climbing, while housework becomes difficult and cleaning of a large house becomes burdensome. Also, weaknesses like failing eyesight interfere with modest home repair and make a dark, cluttered house perceived dangerous, while the loss of sense of feeling exposes old people to extreme thermal conditions and subjects them to incessant frequenting of the health clinic. When the current housing situation reveals these inevitable experiences of the user, it shows that the housing unit is no longer appropriate to successful ageing, thereby, indicate the need to review the initial design consideration of the building.

To achieve a sustainable design, considerations that project to support the inevitable biological change in user is expected. The decline in physical strength 
makes walking becomes difficult. Therefore, houses with stepped floors, stairs, poor space planning and arrangement of interior become unsuitable. Most old people have difficulty in adjusting from light to dark due to a decline in peripheral vision. An older person's eyes are particularly weak in dim light and have less ability to see close objects.

Also, two areas of the home that were most cited as causing difficulty were the stairs and bathroom/toilet in the literature. Given this, there may be a need to consider varying the colour of floor finishes to differentiate a stepped floor area or reduce the step riser to an average walking height. Another way is to adopt an open plan method of designing. Consideration of decline physical strength in users of design product will reduce falling occurrence and complications of space planning at old age.

\section{Methodology}

This study cut across four out of six geopolitical zones in Nigeria and the states selected in each of the zones are where we have a higher population size of older adults. The specific areas picked are Akure in Ondo state (South-West), Asaba in Delta state (South-South), Onitsha in Anambra state (South-East) and Gwagwalada and Abuja municipal in the Federal Capital Territory (North Central) (Figure 1). The essence is to cover as many ethnic groups to ascertain a generalised study result.

Buildings were randomly picked within the streets in the selected area, and where the selected building has no occupant in the considered age category, the next building to it is chosen for the study. The participants studied are of age bracket 60 years and above, occupying their owned houses and have experience of their building and possible adjustment made so far during their stay. An interview was conducted following an already prepared structured questionnaire comprising of four sections that cover respondents' education and financial status, the building material and method of construction, their experience of the selected interior spaces and possible area of improvement required.

The first two sections are close-ended where options are given to the respondents to pick from, while the other two sections that explore respondents' experiences of their interior spaces under study and area of required improvement in their buildings are open-ended. A total of four hundred participants interviewed between February and June of the year 2018 were used for this study. Other instruments like observation note and voice-activated tape recorder were also used to capture the participants' responses and expressions; each interview lasted an average of 15 minutes. The study also adopted the review of relevant literature which allowed for in-depth knowledge of factors underpinning the respondents' views to give credible and valid results.

The data collected were later transpose using the descriptive statistical method to various categories. Content analysis was further used to correlate respondents' financial status, housing situation, and challenges in performing daily routines 


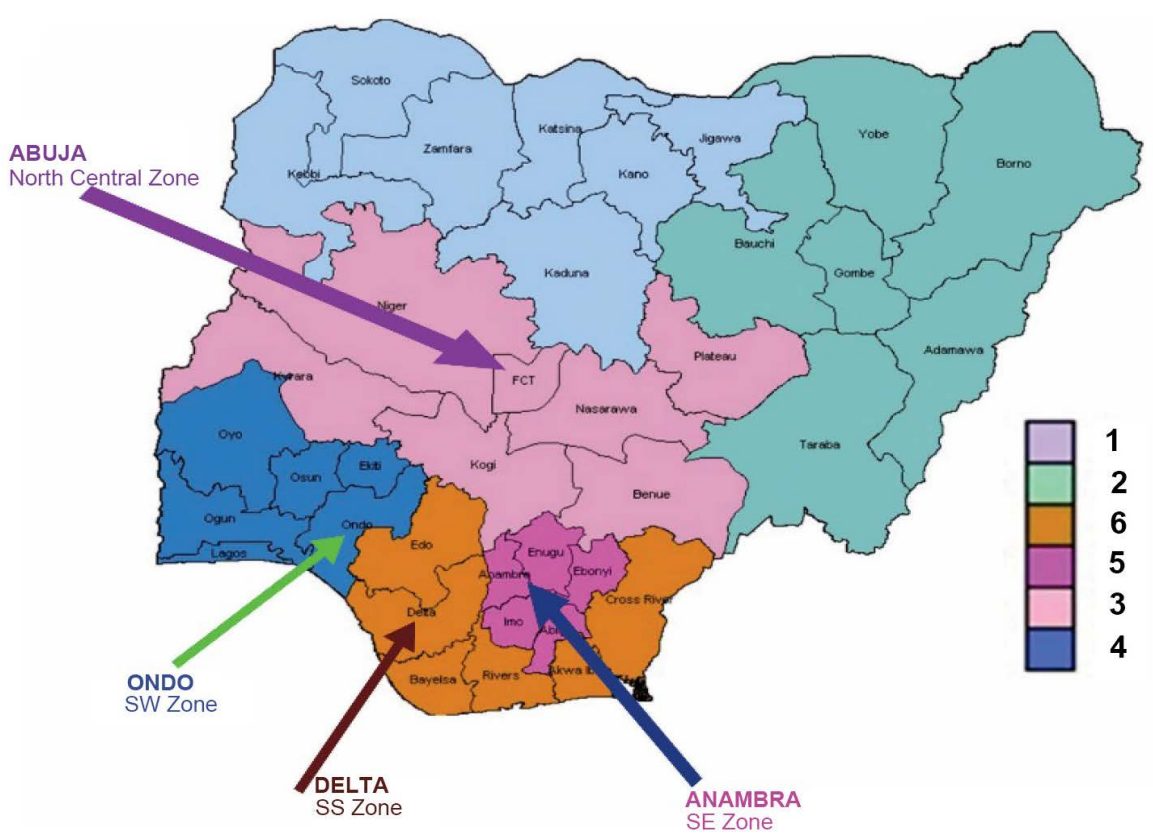

Figure 1. Map showing the study areas in the four geopolitical zones selected.

in their homes in other to determine the infusing elements needed to improve the housing facility sustainably.

\section{Result and Discussion}

This section shows the demographic status of the respondents, education and financial condition, the component of the buildings occupied, the experience of selected indoor space and perception of areas that improvements are needed. Four interior spaces were studied, which are the living room, bedroom, kitchen and toilet. The interview took record of the material of construction, fitting and finishes used in the interior spaces studied. Questions were asked about the performance of the interior spaces under study in its support of all activities of daily living performed by the respondents. The respondents' demographic status is detailed in Table 1. Responses were integrated, and general inferences were drawn through content analysis method, looking into the implication of materials used for construction, use of stairs in the building, window and door types, and material finishes choices among others. The consequent subsection unfolds the details.

\subsection{Typical of the Respondents}

Table 1 shows that $60 \%$ of the respondents are female and of average age between 60 and 70 years. The table also shows the record of a good number of both literate and uneducated old adult, the majority of whom are living in the family house, with spouse or house help. The table shows that only $10 \%$ of respondents interviewed live alone.

Also, the table further shows that majority of the respondents rely on family (33\%) and pension (28\%) with a mean average income between N21,000 and 
Table 1. Demographic detail of the Aged interviewed in the studied areas.

\begin{tabular}{|c|c|c|}
\hline Variable & Frequency & Percentage \\
\hline \multicolumn{3}{|l|}{ Gender } \\
\hline Male & 160 & 40.0 \\
\hline Female & 240 & 60.0 \\
\hline \multicolumn{3}{|l|}{ Age } \\
\hline $60-70$ & 235 & 58.8 \\
\hline $70-80$ & 70 & 17.6 \\
\hline $80-90$ & 70 & 17.6 \\
\hline Above 90 & 25 & 5.9 \\
\hline \multicolumn{3}{|l|}{ Education } \\
\hline None & 105 & 26.3 \\
\hline Informal & 38 & 09.5 \\
\hline Primary cert & 47 & 11.5 \\
\hline Sec cert & 105 & 26.3 \\
\hline Tertiary & 105 & 26.3 \\
\hline \multicolumn{3}{|l|}{ State of living } \\
\hline Alone & 42 & 10.5 \\
\hline With spouse & 126 & 31.6 \\
\hline With family & 211 & 52.6 \\
\hline With house help & 21 & 5.3 \\
\hline \multicolumn{3}{|l|}{ Income source } \\
\hline Wages & 89 & 22.2 \\
\hline Pension & 111 & 27.8 \\
\hline Self-support & 23 & 5.6 \\
\hline Family & 133 & 33.3 \\
\hline NGO & 44 & 11.1 \\
\hline \multicolumn{3}{|l|}{ Monthly income } \\
\hline $10,000-20,000$ & 200 & 50.0 \\
\hline $21,000-40,000$ & 111 & 27.8 \\
\hline $61,000-80,000$ & 23 & 5.6 \\
\hline $81,000-100,000$ & 43 & 11.1 \\
\hline Above 100,000 & 23 & 5.6 \\
\hline \multicolumn{3}{|l|}{ Income regularity } \\
\hline Always & 200 & 50.0 \\
\hline Sometimes & 178 & 44.4 \\
\hline Rarely & 22 & 5.6 \\
\hline \multicolumn{3}{|l|}{ Years spend } \\
\hline $1-5$ & 43 & 11.1 \\
\hline $6-10$ & 111 & 27.8 \\
\hline $11-15$ & 67 & 16.7 \\
\hline
\end{tabular}


Continued

\begin{tabular}{ccc}
\hline $16-20$ & 156 & 38.9 \\
Above 20 & 23 & 5.6 \\
\hline Stayed most time & & \\
\hline At home & 94 & 23.5 \\
Inside personal shop & 212 & 52.9 \\
With friends & 47 & 11.8 \\
Go visiting & 47 & 11.8 \\
\hline
\end{tabular}

$\mathrm{N} 40,000$ (mean score of 3.17). 50\% of the respondents enjoy a regular income while about $5.6 \%$ hardly enjoy regular income. Likewise, it shows in the table that $55 \%$ of the respondents lived an average of 10 years in the houses under study and the majority run a personal shop that helps social connectivity. This study coincidentally has ably represented every category that measures educational status. The study has equal representation of those that have neither formal nor informal education, those that study to secondary level and tertiary level. It shows, therefore, that the result of this study is not influenced by education status.

The study also revealed that at old age, the majority of the aged rely on their family for financial assistance, in addition to their pension for some that have served at civil services. Also, it was discovered that the respondents' adaptable measure for financial stability is by using the monthly stipends received to run a retail shop that, although did not generate much, still earn them some financial independence at the laxity of their financial source.

The respondents posit that their financial strength only aid support for food, clothing and minor commitments like services bills, house owners' association bills, among others. Conditions like improper building orientation that deprives some useful area in the interior of adequate lighting, limited control of airflow in the interior, perception of safety in some spaces, properties of wall material used to build and many more have result the aged to additional spending on health matters, purchase of additional features to improve safety, change of clothing to fit different seasons, and on artificial lighting services.

The response from the interview collated reveals that the cost implication resulted from the inability of their housing to sustain these inconsistent requirements ageing poses have subjected many of them to a concomitant peril of sick today and healthy tomorrow syndrome. Also, the general custom that places the responsibility of care and support of older people in their family has resulted in nonchalance of the government. As stated by the respondents, the pension most aged depends on are not paid frequently, the government has no support strategy for the aged, and the non-governmental agencies lack moral to do. Therefore, a sustainable house that will not pose a financial burden on the users that have grown pass working age needs to be sought to improve independent living at old age. 


\subsection{The Material Components of the Buildings Occupied}

Table 2 shows the type of houses the aged interviewed are living in and the component materials used for the wall, doors, windows, and roofing. Almost $60 \%$ of the interviewed elders live in a bungalow apartment that has a very few or no step, $29 \%$ in a raised bungalow and only $11 \%$ in a storey building. Majority of the building wall is of sandcrete block material, only $24 \%$ was built with mud material. Sliding window with aluminium frame is the most common window type, while only $11 \%$ is a louvred window. The metal door was used mainly for the doors directly opening to the exterior of the building, while the majority of the interior doors are of wooden material. Almost $60 \%$ of the roofing covering are of old zinc material, while $35 \%$ are of long-span aluminium.

Further, Table 3 shows the types of finishes applied to the four interior spaces under study. In most living rooms of the respondents interviewed, tiles were used for $55 \%$ of the floors, $70 \%$ of the walls are cement screed and not painted, $69 \%$ have asbestos ceiling finishes, and $75 \%$ perceives that the lighting of the living room is inadequate. In the kitchen, almost $78 \%$ of the floors are tiled, 59\% of the wall have cement screed, about $67 \%$ also have asbestos ceiling finishes, and $73 \%$ complain of inadequate brightness.

Table 2. Stock of building components used in the Aged interviewed houses.

\begin{tabular}{|c|c|c|}
\hline Variables & Frequency & Percentage \\
\hline \multicolumn{3}{|l|}{ House type } \\
\hline Bungalow & 235 & 58.8 \\
\hline Bungalow with raised steps & 118 & 29.4 \\
\hline Storey & 47 & 11.8 \\
\hline \multicolumn{3}{|l|}{ Wall material } \\
\hline Sandcrete plastered & 259 & 64.7 \\
\hline Sandcrete not plastered & 47 & 11.8 \\
\hline Laterite plastered & 94 & 23.5 \\
\hline \multicolumn{3}{|l|}{ Window material } \\
\hline Aluminium with glass-sliding & 200 & 50.0 \\
\hline Aluminium with glass-casement & 44 & 11.1 \\
\hline Wooden window & 112 & 27.8 \\
\hline Aluminium louvered & 44 & 11.1 \\
\hline \multicolumn{3}{|l|}{ Roofing sheet } \\
\hline Aluminium & 141 & 35.3 \\
\hline Zinc & 235 & 58.8 \\
\hline Asbestos & 24 & 5.9 \\
\hline \multicolumn{3}{|l|}{ Door material } \\
\hline Steel & 125 & 31.3 \\
\hline Aluminium with glass & 25 & 6.3 \\
\hline Wood & 250 & 62.5 \\
\hline
\end{tabular}


Table 3. Details of the material finish used in the interior of the buildings.

\begin{tabular}{|c|c|c|c|c|}
\hline Variables & Lounge \% & Kitchen \% & Bedroom \% & Toilet \% \\
\hline \multicolumn{5}{|l|}{ Wall } \\
\hline Screed & 68.8 & 58.8 & 54.5 & 53.8 \\
\hline Paint & 25.0 & 35.3 & 36.4 & 23.1 \\
\hline Wall paper & -- & 5.9 & 9.1 & -- \\
\hline Wood & 6.3 & -- & -- & -- \\
\hline Tile & -- & -- & -- & 23.1 \\
\hline \multicolumn{5}{|l|}{ Floor } \\
\hline Terrazzo & 11.1 & 11.1 & 14.3 & 12.5 \\
\hline Tile & 55.6 & 77.8 & 57.1 & 87.5 \\
\hline Cement screed & -- & 11.1 & -- & -- \\
\hline Carpet & 11.1 & -- & 14.3 & -- \\
\hline Wood & 11.1 & -- & -- & -- \\
\hline Rug & 11.1 & -- & 14.3 & -- \\
\hline \multicolumn{5}{|l|}{ Ceiling } \\
\hline Asbestos & 69.2 & 66.7 & 72.7 & 91.7 \\
\hline Wood & -- & 6.7 & -- & -- \\
\hline Pop & 23.1 & 20.0 & 18.2 & -- \\
\hline Concrete & 7.7 & 6.7 & 9.1 & 8.3 \\
\hline \multicolumn{5}{|l|}{ Brightness } \\
\hline Very adequate & -- & -- & -- & 7.1 \\
\hline Adequate & 16.7 & 28.6 & 27.3 & 42.9 \\
\hline Inadequate & 75.0 & 71.4 & 72.7 & 50.0 \\
\hline Very inadequate & 8.3 & -- & -- & -- \\
\hline
\end{tabular}

Not as different is the bedroom as $73 \%$ uses asbestos ceiling finishes, $57 \%$ of the floors are tiled, $55 \%$ of the walls are cement screed, and $73 \%$ posits inadequate lighting. However, a bit of difference is reported of the toilet space, as only half of the respondents perceived their toilet lighting to be insufficient. Almost $92 \%$ of the toilet space has an asbestos ceiling, $88 \%$ of the floors are tiled, and about $54 \%$ of the walls are cement screed.

\subsection{Users' Experience of Their Interior Spaces}

The report gotten from the respondents reveals that the professionals did not design the majority of the houses that have very minimal or no step. Most of the ones designed by the professionals are characterised by appealing aesthetics, where materials were selected to fit into the modern trend of housing, and the interiors spaces are either stepped up or down to each other at a riser height of $200 \mathrm{~mm}$ maximum. Ironically, only the aged living in the house that was not designed by professionals report a positive perception of good living in the interior spaces, not bordered about safety and requires minor changes in their interior. 
Those that are living in raised bungalow or storey buildings complain of the difficulty in climbing, especially those stair or steps without two-sided railings. Some living in storey building report to have relocated to the ground floor converted a space meant for another function into a bedroom space to avoid climbing. Those living in the interior that has varies of floor level report that they regret the consequence of the design product they have once loved, especially at the time of their life that the financial implication of renovation is not affordable. It is worthy of note to add that the houses without professional touch, but fits into the present need of the users at old age was not planned for. It was financial incapacity that limited their aspiration as at the time of construction. Therefore, it shows that neither the house owners nor the professionals consider the future need that ageing progression poses at the time of design and construction of the building.

Also, Table 2 and Table 3 show that the majority of the building walls of the respondents are plastered with very few painted in all the interior spaces studied. Asbestos was also used for the ceiling finish, while the majority of the floors are tiled. The reports from the respondents' reveal the perception of lighting inadequacy in all the interior spaces studied. This is not unexpected when we consider the wall and ceiling finish used in these old people interior Vis a Vis their building orientation in maximising natural lighting.

The asbestos sheet is grey in colour, and the cement screed also does come out in a darker grey colour hue. With this scenario, it is expected that a greater level of lighting would be absorbed and the value of intensity will be low. Therefore, a design that orientates for better penetration of natural lighting, or the used of reflective material for furniture works would have improved the lighting situation in the interior.

Likewise, widespread usage of sandcrete wall material for construction and sliding window presented itself as a bad choice at old age. The respondents explained that most time, little or no difference is felt in both the interior and exterior of their residential spaces. Most times the temperature is relatively the same in their interior just as the exterior in both hot and cold seasons. Since the sandcrete wall does absorb the temperature of the external space completely, there is a need to control other sources of airflow to the sufficient thermal condition that brings comfort to the old ones. Although the sliding window operation reduces the allowance of airflow to $50 \%$, sometimes $50 \%$ might still be disproportionate. This needed consideration as the study has shown that loss of feeling makes the aged vulnerable to thermal discomfort. The respondents report that usage of heavy clothing has been the adaptable measure of dealing with the thermal condition of their interior spaces, mostly in the bedroom.

Furthermore, Table 2 shows that aluminium and zinc materials are the common materials used as roof covering of the respondents' buildings. These materials are permeable to sound, and as a potential contributor to noise pollution in building disturb through the stretching and contrasting responses to climate change. Also, the asbestos ceiling finish used is also a poor soundproof material. 
The respondents report that the noise pollution constituted by these prevalent materials is worse during the rainy season. Therefore, a more absorbing material such as wood, common in this part of the world, would have sufficed if used as ceiling finish against asbestos.

\section{Recommendation and Conclusion}

This paper has identified and emphasised consideration of the biological change of users as an essential way of improving the satisfaction level of the design product. This paper considered the old people residential interior spaces vis-à-vis the materials used for construction and the selected finished used in the interior spaces studied. The study shows that the level of financial independence declines as people age, thus, housing that requires modification needs to adjust to future user needs to be placed an unbearable financial burden on the majority at old age. This study shows that the inability to make these necessary adjustments has further subjected many old individuals with financial incapacity to declined health.

Furthermore, the study shows that majority of the respondents use the modern material for construction with prevailing walling material being sandcrete block. This permeable wall material is disadvantageous in climate adaptation. Thus, there was evidence of the harsh thermal condition. Also, there was evidence of poor light reflection in the interior due to factors such as poor building orientation, the permeability of the material, and shape and size of the building. The usage of aluminium and zinc material for roofing without insulation has greatly contributed to noise pollution through contrasting adjustment to climatic condition.

\subsection{Recommendation}

Although the elderly respondents interviewed indicate a sense of contentment to their home and surroundings which can be considered as legitimate reflexes, some matters of concern have also been highlighted in this study and some of the main policy implications of the findings are outlined below:

1) Assessment of building regulation that includes risks and hazards of design methodology could be made, and the required adaptations could be suggested, e.g. fitting of handrails at both sides of steps or reduce the step riser to walking height, use of ramps and anti-skid flooring.

2) Assessment of building material performance regarding light reflection and thermal absorbent capacity. This will serve as a guide in the selection of material for construction and finishes to attain the required thermal condition and better illumination in the residential interior.

3) Assessment of curriculum of architecture education to enlighten the professionals under training about fundamental studies of behavioural and social humanities studies. Exposure to such foundational courses during architectural training in school will foster design product envisioned through the users' perspective. 
4) There is also a need for more research on the improvement of indigenous materials for construction. The indigenous materials are a better fit into the $\mathrm{Ni}$ geria climate condition, are age-friendly and will also reduce the cost of construction.

\subsection{Conclusion}

The study shows that the residential houses are a critical component of measuring successful ageing and quality of life at old age, and that the performance of the interior spaces in creating an optimal living environment at old age should be the critical consideration of designers and structural support of design methodology. Therefore, research should be geared towards such a design product that can accommodate the biological change of the users, which is the key factor that reduces satisfaction at an older age. In the quest for sustainable design that can suit the aged, concepts like universal design, design for an intergenerational relationship and age-friendly housing have been promoted, although the consideration is to guide modification of housing at old age. While the existing concepts are capturing concern for a proper renovation of the existing house, there is need to further research on housing facility that is all age compliance to foster an improved design product that will not require future modification.

\section{Conflicts of Interest}

The authors declare no conflicts of interest regarding the publication of this paper.

\section{References}

[1] Henilane, I. (2016) Housing Concept and Analysis of Housing Classification. Baltic Journal of Real Estate Economics and Construction Management, 4, 168-179. https://doi.org/10.1515/bjreecm-2016-0013

[2] Rachel, E. (2015) The Concept of Sustainable Development: Definition and Defining Principle. Brief for GSDR 2015, Florida International University. https://sustainabledevelopment.un.org/content/documents/5839GSDR\%202015_SD _concept_definiton_rev.pdf

[3] Abu Hassan, A.B., Khor, S.C. and Rahmawaty (2011) Sustainable Housing Practices in Malaysia Housing Development: Towards Establishing Sustainability Index. International Journal of Technology, 1, 84-93.

[4] Choguill, C.L. (2007) The Search for Policies to Support Sustainable Housing. Habitat International, 31, 143-149. https://doi.org/10.1016/j.habitatint.2006.12.001

[5] Singh, V.S. and Pandey, D.N. (2012) Balancing Environment with Urban Growth in India. RSPCB Occasional Paper No. 6/2012.

https://dlc.dlib.indiana.edu/dlc/bitstream/handle/10535/8794/Pandey.pdf?sequence $=1$

[6] Mulliner, E., Smallbone, K. and Maliene, V. (2013) An Assessment of Sustainable Housing Affordability Using a Multiple Criteria Decision-Making Method. Omega, 41, Article ID: 270279. https://doi.org/10.1016/j.omega.2012.05.002

[7] Ibem, E.O. and Azuh, D.E. (2011) Framework for Evaluating the Sustainability of 
Public Housing Programmes in Developing Countries. Journal of Sustainable Development and Environmental Protection, 1, 24-39.

[8] Gupta, R. and Chandiwala, S. (2008) Achieving Low Carbon Buildings Using the Code for Sustainable Homes in the UK. International Journal of Low-Carbon Technologies, 4, 187-196. https://doi.org/10.1093/ijlct/ctp018

[9] Winston, N. (2008) Urban Regeneration for Sustainable Development: The Role of Sustainable Housing. European Planning Studies, 17, 1781-1796. https://doi.org/10.1080/09654310903322306

[10] Oh, J.H. and Kim, S. (2009) Ageing, Neighbourhood Attachment, and Fear of Crime: Testing Reciprocal Effects. Journal of Community Psychology, 37, 21-40. https://doi.org/10.1002/jcop.20269

[11] Tanyi, P.L., André P. and Mbah, P. (2018) Care of the Elderly in Nigeria: Implications for Policy. Cogent Social Sciences, 4, Article ID: 1555201. https://doi.org/10.1080/23311886.2018.1555201

[12] Golant, S.M. (2008) Commentary: Irrational Exuberance for the Ageing in Place of Vulnerable Low-Income Older Homeowners. Journal of Aging and Social Policy, 20, 379-397. https://doi.org/10.1080/08959420802131437

[13] Onanuga, O.A. and Attoye, D.E. (2016) Influence of Recreation Spaces on the Aged Health in the Urban Fringes of Akure, Nigeria. Research on Humanities and Social Sciences, 6, 44-51.

[14] Mohit, M.A., Ibrahim, M. and Rashid, Y.R. (2010) Assessment of Residential Satisfaction in Newly Designed Public Low-Cost Housing in Kuala Lumpur, Malaysia. Habitat International, 34, 18-27. https://doi.org/10.1016/j.habitatint.2009.04.002

[15] Aduwo, E.B., Ibem, E.O. and Opoko, A.P. (2013) Residents' Transformation of Dwelling Units in Public Housing Estates in Lagos, Nigeria: Implications for Policy and Practice. International Journal of Education and Research, 1, 1-20.

[16] Onanuga, O.A., Ayoola, H.A. and Oviasogie, C.O. (2017) Perception of Indoor Spatial Quality in Public Residences in Akure, Nigeria. International Journal of Development Research, 7, 1-9.

[17] Amao, F.L. and Ilesanmi, A.O. (2013) Housing Delivery in Nigeria: Repackaging for Sustainable Development. International Journal of African and Asian Studies, 1, 80.

[18] Akinyode, B.F. and Tareef, H.K. (2014) Bridging the Gap between Housing Demand and Housing Supply in Nigerian Urban Centres: A Review of Government Intervention So Far. British Journal of Arts and Social Sciences, 18, 94-107.

[19] Gans, H. (1962) The Urban Villagers Group and Class in the Life of Italians. Free Press, New York.

[20] Raven, J. (1967) Sociological Evidence on Housing. The Home Environment. Architectural Review, 161, 236-245.

[21] Oladapo, A.A. (2006) A Study of Tenant Maintenance Awareness, Responsibility and Satisfaction in Institutional Housing in Nigeria. International Journal of Strategic Property Manage, 10, 217-231. https://doi.org/10.3846/1648715X.2006.9637554

[22] Jiboye, A.D. (2014) The Significance of House-Type as a Determinant of Residential Quality in Osogbo, Southwest Nigeria. Frontier of Architectural Research, 3, 20-27. https://doi.org/10.1016/j.foar.2013.11.006

[23] Jiboye, A.D. and Ogunshakin, L. (2010) The Place of the Family House in Contemporary Oyo Town, Nigeria. Journal of Sustainable Development, 3, 117-128.

[24] UN-HABITAT (2005) Indigenous Peoples' Right to Adequate Housing a Global Review. United Nations Housing Rights Programme Report No. 7, Nairobi. 
[25] Dawan, P.D. (1994) Urban Development and Population Repositioning Abuja, Nigeria. Ekistics, 366, 216-217.

[26] Syddall, H., Roberts, H.C., Evandrou, M., Cooper, C., Bergman, H. and Sayer, A.A. (2010) Prevalence and Correlates of Frailty among Community-Dwelling Older Men and Women: Findings from the Hertfordshire Cohort Study. Age and Ageing, 39, 197-203. https://doi.org/10.1093/ageing/afp204 